\title{
BMJ Open Sex differences in type and occurrence of adverse reactions to opioid analgesics: a retrospective cohort study
}

Guilherme S Lopes (D) ,' Suzette Bielinski (i) , ${ }^{1}$ Ann M Moyer, ${ }^{2}$ Debra J Jacobson, ${ }^{1}$ Liwei Wang, ${ }^{1}$ Ruoxiang Jiang, ${ }^{1}$ Nicholas B Larson, ${ }^{1}$ Virginia M Miller, ${ }^{3}$ Ye Zhu, ${ }^{1}$ Dana C Cavanaugh, ${ }^{1}$ Jennifer St Sauver (i) ${ }^{1}$

To cite: Lopes GS, Bielinski S, Moyer AM, et al. Sex differences in type and occurrence of adverse reactions to opioid analgesics: a retrospective cohort study. BMJ Open 2021;11:e044157. doi:10.1136/ bmjopen-2020-044157

- Prepublication history and additional online supplemental material for this paper are available online. To view these files, please visit the journal online (http://dx.doi.org/10. 1136/bmjopen-2020-044157)

Received 25 August 2020 Accepted 15 June 2021

Check for updates

(C) Author(s) (or their employer(s)) 2021. Re-use permitted under CC BY-NC. No commercial re-use. See rights and permissions. Published by BMJ.

${ }^{1}$ Department of Quantitative Health Sciences, Mayo Clinic, Rochester, Minnesota, USA 2Department of Laboratory Medicine and Pathology, Mayo Clinic, Rochester, Minnesota, USA

${ }^{3}$ Department of Surgery and Department of Physiology and Biomedical Engineering, Mayo Clinic, Rochester, Minnesota, USA

Correspondence to Dr Guilherme S Lopes; lopes.guilherme@mayo.edu

\section{ABSTRACT}

Objectives Sex as a biological variable affects response to opioids. However, few reports describe the prevalence of specific adverse reactions to commonly prescribed opioids in men and women separately. A large cohort was used to investigate sex differences in type and occurrence of adverse reactions associated with use of codeine, tramadol, oxycodone and hydrocodone.

Design Retrospective cohort study.

Setting Participants in the Right Drug, Right Dose, Right Time (RIGHT) Study.

Participants The medical records of 8457 participants in the RIGHT Study who received an opioid prescription between 1 January 2004 and 31 December 2017 were reviewed $61 \%$ women, $94 \%$ white, median age (Q1Q3) $=58(47-66)$.

Primary and secondary outcome measures Adverse reactions including gastrointestinal, skin, psychiatric and nervous system issues were collected from the allergy section of each patient's medical record. Sex differences in the risk of adverse reactions due to prescribed opioids were modelled using logistic regression adjusted for age, body mass index, race and ethnicity.

Results From 8457 participants (of which 449 (5.3\%) reported adverse reactions), more women (6.5\%) than men $(3.4 \%)$ reported adverse reactions to at least one opioid $(\mathrm{OR}(95 \% \mathrm{Cl})=2.3$ (1.8 to 2.8), $\mathrm{p}<0.001)$. Women were more likely to report adverse reactions to tramadol $(\mathrm{OR}(95 \% \mathrm{Cl})=2.8(1.8$ to 4.4$), \mathrm{p}<0.001)$ and oxycodone $(0 \mathrm{R}(95 \% \mathrm{Cl})=2.2(1.7$ to 2.9$), \mathrm{p}<0.001)$. Women were more likely to report gastrointestinal $(0 \mathrm{R}(95 \% \mathrm{Cl})=3.1$ (2.3 to 4.3), $\mathrm{p}<0.001)$, skin $(\mathrm{OR}(95 \% \mathrm{Cl})=2.1(1.4$ to 3.3$)$, $\mathrm{p}=0.001)$ and nervous system issues $(\mathrm{OR}(95 \% \mathrm{Cl})=2.3$ (1.3 to 4.2$), p=0.004$ ).

Conclusions These findings support the importance of sex as a biological variable to be factored into pain management studies.

\section{INTRODUCTION}

Opioid analgesics are among the most commonly prescribed medications in the USA, with 51 opioid prescriptions per 100 persons being filled in 2017. ${ }^{1}$ Despite the widespread use of opioids, previous research has documented important individual differences in response to these medications. ${ }^{2}{ }^{3}$
Strengths and limitations of this study

- Sex differences in opioid response were investigated using a large sample size.

- Outcomes and patient characteristics were extracted directly from the electronic health record.

- Complete follow-up on reported information after opioid prescription was incorporated.

- We missed adverse reactions that patients did not report to their healthcare providers.

- Our cohort may not be generalisable to non-white groups.

In particular, response to opioids, including adverse reactions, may differ between males and females. ${ }^{4-9}$ Sex differences in rates of adverse reactions have been observed in adults, ${ }^{7}$ children, ${ }^{10}$ tobacco smokers, ${ }^{11}$ individuals with opioid use disorder ${ }^{12}$ and postoperative patients. ${ }^{13}$ In addition, these differences have been observed for different opioids, such as morphine, ${ }^{14}{ }^{15}$ oxycodone, ${ }^{11}$ sufentanil ${ }^{16}$ and fentanyl. ${ }^{17}$

Collectively, these data suggest that biological sex influences effects of and response to the general class of opioids. However, characterisation of the type and number of adverse reactions by opioid class and sex needs further investigation. For example, most studies investigating sex differences in response to opioids reported that women have a higher risk of experiencing nausea and vomiting after opioid use. ${ }^{18}$ Findings are less consistent for sex differences on respiratory depression, with some studies reporting a higher risk for women, ${ }^{10} 1920$ in contrast to others that observed no sex difference. ${ }^{1721}$ Some studies reported sex-related differences of other adverse reactions, such as that women have a higher risk of experiencing reduced motor function, ${ }^{16}$ dizziness,${ }^{22}$ negative feelings, ${ }^{23}$ dry mouth, ${ }^{15}$ hypoxia, ${ }^{24}$ headache ${ }^{9}$ and suicidal ideation, ${ }^{25}$ while men 
are more likely to experience sleepiness ${ }^{26}$ and to die of opioid-related causes. ${ }^{27}$

Previous studies reporting sex differences in response to opioids have relied on small sample sizes $(\mathrm{n}<50) .{ }^{11} 12$ 21-23 Studies with larger sample sizes $(n>1000)$ have focused on relatively uncommon opioids in general clinical practice, such as fentanyl ${ }^{17}$ and sufentanil. ${ }^{16}$ Those with large sample sizes and focusing on more common opioids (eg, morphine) limited their reports to non-clinical adverse reactions (eg, dose escalation ${ }^{27}$ ) or combined opioids from different classes, ${ }^{18}$ even though opioids from different classes may differ in associated side effects (eg, codeine is more associated with nausea and hallucinations than hydrocodone and oxycodone).$^{28}$ Additionally, these previous studies have focused on very different populations (eg, patients with acute or chronic pain ${ }^{16} 1827$ and healthy volunteers ${ }^{12}{ }^{21}$ ), making it difficult to assess the risk of adverse effects in the general population. In short, although several studies have documented sex differences in response to opioids, very few reports at the population level or using large cohorts described specific clinical adverse reactions to commonly prescribed opioids separately in men and women.

Understanding the type and occurrence of adverse reactions in men and women may allow clinicians to better individualise treatments, thereby optimising pain control and reducing adverse reactions related to opioid use. Sex-specific rates of reported adverse reactions associated with use of the four most commonly prescribed opioids (ie, codeine, tramadol, oxycodone and hydrocodone) were examined among persons participating in a large cohort study to understand the impact of sex as a biological variable on responses to commonly prescribed medications ('Right Drug, Right Dose, Right Time (RIGHT) Study'). ${ }^{29-31}$

\section{METHODS}

\section{Study participants}

Details of the RIGHT Study have been previously reported. ${ }^{29-31}$ Briefly, 11098 participants in the Mayo Clinic Biobank consented to participate in a study of preemptive genotyping to understand the effect of variation in genes related to drug metabolism on drug outcomes. Details of the Mayo Clinic Biobank are reported elsewhere. ${ }^{32}$ Briefly, the goal of the Biobank was to establish a population from which to draw controls for research studies. Therefore, patients were actively recruited from primary care departments $(76 \%)$ and specialty clinics including orthopaedics (10\%), executive health $(4 \%)$, obstetrics/gynaecology (3\%), sports medicine (1\%) and the breast clinic $(1 \%)$. Characteristics of the population are similar to those of the underlying population, but persons in the Biobank are older, have a higher education level, and are more likely to be of White race compared with those who did not participate. The most common medical conditions in this population are hyperlipidaemia (41\%), hypertension (38\%) and osteoarthritis $(30 \%)$.
Pharmacogenomic genotyping results were deposited into the electronic health record (EHR) for use in clinical care, and participants consented to the use of their EHR for research. Since recruitment, five participants have withdrawn their consent for future research. The Mayo Clinic Biobank population characteristics are similar to those of the general population. ${ }^{32}$

\section{Adverse reactions}

Incident opioid-related adverse reactions were collected from the allergy section of the EHR. The allergy section of the EHRs we studied is used to not only document true medication allergies, but also to report all manner of adverse effects or intolerances to medications. ${ }^{33}$ Incidence of opioid allergy is believed to be very rare, ${ }^{34}$ and most patients who report to be allergic to an opioid have instead experienced a side effect that has been misclassified as an allergy. ${ }^{35}$ For this reason, side effects and allergic responses were aggregated into a single 'adverse reactions' category. Adverse reactions associated with an opioid recorded by healthcare providers as semistructured text in the allergy section of Mayo Clinic EHR from 1 January 2004 to 31 December 2017 were extracted using MedTagger. ${ }^{36}$ Reports of adverse reactions within 6 weeks after opioid prescription were extracted. Study personnel with expertise in drug response reporting practices and not related to this study reviewed and structured the free text (eg, 'instantaneous onset of nausea' into 'nausea'), and further organised the structured text into 16 major Medical Dictionary for Regulatory Activities (MedDRA) categories, including gastrointestinal (eg, nausea, constipation), skin and subcutaneous tissue (eg, rash, itching), psychiatric (eg, anxiety, hallucinations) and nervous system (eg, migraine, dizziness). MedDRA is the international medical terminology developed under the auspices of the International Council for Harmonisation of Technical Requirements for Pharmaceuticals for Human Use. A list of MedDRA categories is shown in online supplemental file 1 .

\section{Prescriptions}

The Rochester Epidemiology Project (REP) research infrastructure was used to identify all participants in the RIGHT Protocol who were prescribed codeine, tramadol, hydrocodone and/or oxycodone in oral form between 1 January 2004 and 31 December 2017 from a local healthcare provider. ${ }^{37}$ We focused on these four opioids because they are commonly prescribed in the general population in the United States. The REP is a medical records-linkage system connecting collaborating clinics, hospitals, and other medical facilities in Minnesota and Wisconsin, United States, and includes data of community members who have agreed to share their medical records for research. RxNorm, a national database of normalised names for clinical drugs, was used to identify all codes for prescriptions that included the ingredients codeine, tramadol, hydrocodone or oxycodone. Formulations intended primarily to treat cough (eg, guaifenesin/ 
codeine) were excluded to focus on prescriptions for pain. We included both immediate release/short acting and sustained release/long acting formulations. A complete list of medications considered is shown in online supplemental file 1 . To exclude instances of prevalent/chronic use prior to the study time frame, participants were excluded if they had been prescribed any of the four opioids within 2 years prior to 1 January 2004.

\section{Statistical analyses}

Patient characteristics at the time of the first prescription were summarised using counts and percentages for categorical variables, and median and quartiles for continuous variables. Sex as a biological variable was retrieved from the electronical medical records. Age was calculated at the date of first opioid prescription. Body mass index (BMI) was retrieved from the medical note closest to the first opioid prescription date $(67 \%$ of participants had their BMI recorded within 2 years of opioid prescription). If a participant had multiple opioid prescriptions within the study time frame, then the earliest prescription was considered in the calculation of age and BMI. Sex differences in age and BMI were evaluated using Wilcoxonrank sum tests. Sex differences in race and ethnicity were estimated using Pearson's $\chi^{2}$ test with Monte Carlo simulated $\mathrm{p}$ values based on 2000 replicates to account for small cell counts. ${ }^{39}$ Prescription rates between men and women were compared separately for each opioid using logistic regression.

Sex differences were evaluated for number and type of adverse reactions from any of four commonly prescribed opioids: codeine, tramadol, oxycodone and hydrocodone. Sex differences in reported adverse reactions were also investigated separately for each of the

(A) Main analysis $(\mathrm{n}=8,457)$

Prescribed at least one opioid within the study coverage

(B) Sensitivity analysis $(\mathrm{n}=8,585)$

Prescribed at least one opioid

(regardless of whether the opioid was prescribed within the study coverage) four opioids. Multivariable logistic regression was used to model sex differences in the risk of having adverse reactions to at least one opioid, and of having adverse reactions by each opioid separately. Finally, multivariable logistic regression was used to model sex differences in the risk of an adverse reaction in at least one of the four most common MedDRA classes (gastrointestinal, skin and subcutaneous tissue, psychiatric and nervous system) due to use of any of the four opioids. Men were considered as the reference group. Models included adjustment for age at first prescription, BMI, race and ethnicity. A two-sided significance level of $\alpha=0.05$ was adopted for all analyses. For the multivariable models, $\alpha$ was corrected to 0.0125 to account for multiple testing (Bonferroni correction).

The main analysis included only participants who were prescribed an opioid during the data collection period (figure 1A). Some participants in the RIGHT study had notes indicating adverse reactions to opioids not captured in the observed prescription data. For example, a participant had a note indicating gastrointestinal issues to oxycodone but an oxycodone prescription could not be found during the study time frame for that participant. The adverse reactions recorded outside the study coverage were assumed to have occurred due to an opioid prescribed prior to the study timeline or at a healthcare institution that was not captured by the REP research infrastructure. ${ }^{38} \mathrm{~A}$ sensitivity analysis was conducted including those participants and adverse reactions (figure 1B), that is, participants who reported at least one adverse event to an opioid prescribed outside the study coverage, akin to oversampling cases in a case-control study. For the sensitivity analysis, estimates were not adjusted for age at first prescription and BMI closest to first prescription

\begin{tabular}{|}
$\begin{array}{c}\text { Adverse reaction to an opioid } \\
\text { prescribed within the study coverage } \\
\text { No }\end{array}$ Yes \\
\hline 0 & 0 \\
\hline 8008 & 449 \\
\hline
\end{tabular}

Adverse reaction to an opioid (regardless of whether the adverse reaction refer to an opioid prescribed within the study coverage)

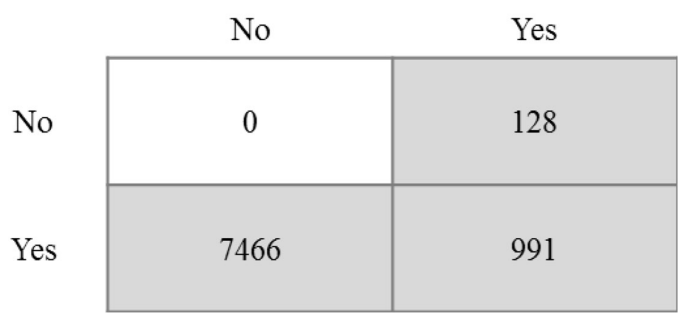

Figure 1 (A) Participants included in main analysis and (B) sensitivity analysis. 
Table 1 Patient characteristics

\begin{tabular}{|c|c|c|c|c|}
\hline \multirow[b]{2}{*}{ Characteristic } & \multirow[b]{2}{*}{ Total } & \multicolumn{2}{|l|}{ Sex } & \multirow[b]{2}{*}{$P$ value } \\
\hline & & Men & Women & \\
\hline Total & 8457 & 3319 (39\%) & $5138(61 \%)$ & $<0.001^{*}$ \\
\hline Median & 58 & 62 & 55 & $<0.001 \ddagger$ \\
\hline Q1-Q3 & $47-66$ & $54-69$ & $44-64$ & \\
\hline \multicolumn{5}{|l|}{ Race, n (\%) } \\
\hline White & 7963 & $3129(94 \%)$ & 4834 (94\%) & $0.299 \S$ \\
\hline Black & 44 & $22(0.7 \%)$ & $22(0.4 \%)$ & \\
\hline Asian/Pacific islander & 69 & $29(0.9 \%)$ & $40(0.8 \%)$ & \\
\hline Mixed/other/unknown & 381 & $139(4.2 \%)$ & $242(4.7 \%)$ & \\
\hline Hispanic & 92 & $34(1 \%)$ & $58(1.1 \%)$ & \\
\hline Unknown & 6 & 1 & 5 & \\
\hline \multicolumn{5}{|l|}{$\mathrm{BMI}\left(\mathrm{kg} / \mathrm{m}^{2}\right)$} \\
\hline Median & 28 & 29 & 27 & $<0.001 \ddagger$ \\
\hline Q1-Q3 & $25-33$ & $26-33$ & $24-32$ & \\
\hline Unknown & 1 & 0 & 1 & \\
\hline \multicolumn{5}{|c|}{ Opioid prescriptionsף, n (\%) } \\
\hline Codeine & 1478 & $513(12 \%)$ & $965(14 \%)$ & $<0.001^{\star *}$ \\
\hline Tramadol & 3723 & $1427(32 \%)$ & 2296 (34\%) & $0.032^{\star \star}$ \\
\hline
\end{tabular}

${ }^{*} \mathrm{P}$ value from one proportion $z$-test.

†First among any type of opioids considered.

$\ddagger \mathrm{P}$ value from Wilcoxon-rank sum test.

$\S P$ value from $\chi^{2}$ test (simulated $p$ value based on 2000 replicated).

ПOpioid prescriptions between 1 January 2004 and 31 December 2017; participants could be prescribed more than one opioid.

${ }^{\star \star P} \mathrm{P}$ value from logistic regression (Wald Z-test).

BMI, body mass index.

because these covariates could not be calculated without a prescription date.

\section{RESULTS}

A total of 8457 participants were included in our study, of which $449(5.3 \%)$ reported adverse reactions. Participant characteristics and opioid prescriptions are shown in table 1. Most participants were women (61\%). Men were older (median $=62$ vs 55, $\mathrm{p}<0.001)$, and had a higher BMI (median=29 vs 27, $\mathrm{p}<0.001$ ). Oxycodone was the most often prescribed opioid in this cohort $(41 \%$ of all prescriptions). Women were more likely than men to be prescribed codeine $(p<0.001)$ and tramadol $(p=0.032)$. A total of 456 participants had a note in the allergy section indicating an adverse reaction to at least one opioid among the opioids included in this study (ie, codeine, tramadol, oxycodone and hydrocodone). Seven participants had vague descriptions in their notes (eg, 'triggers issues', 'didn't like it', 'does not recall specifics'), thus not allowing for MedDRA classification and therefore were excluded from further analyses. Therefore, for the main analysis, a total of 449 participants were considered to have an opioid-associated MedDRA class. These participants yielded a total of 648 occurrences of adverse reaction to opioids, as participants could report adverse reactions to more than one opioid (online supplemental file 1). The four most common MedDRA classes accounted for $494(76 \%)$ of all adverse reaction occurrences. Online supplemental figure 1 depicts the overlap in type and occurrence of adverse reactions by opioid.

Approximately twice as many women (6.5\%) compared with men $(3.4 \%)$ exposed to any opioid reported a related 
Table 2 Sex differences in the risk of having a note in the allergy section indicating adverse reactions to opioid (men as reference group) among participants in the right study who were prescribed at least one opioid between 1 January 2004 and 31 December $2017(n=8457)$

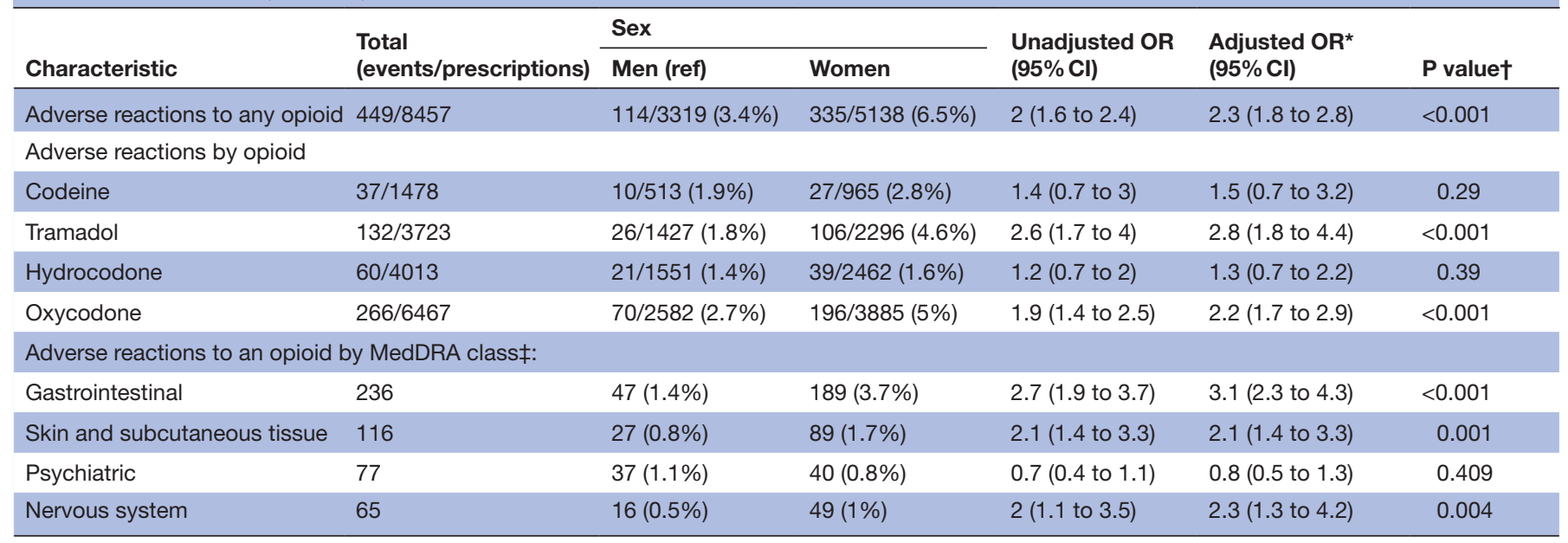

*Adjusted for age at prescription, BMI, race and ethnicity.

†P values for multivariable (adjusted) models; $\alpha$ was set to 0.0125 for a two-sided significance to account for multiple comparisons (Bonferroni correction). $\ddagger$ Among those who were prescribed an opioid within our study coverage (men, $n=3319$; women, $n=5138$ ).

BMI, body mass index; MedDRA, Medical Dictionary for Regulatory Activities.

adverse reaction (adjusted OR $(95 \% \mathrm{CI})=2.3$ (1.8 to 2.8), $\mathrm{p}<0.001$; see table 2). Women had a higher risk of having an adverse reaction to tramadol (adjusted OR $(95 \% \mathrm{CI})=2.8(1.8$ to 4.4$), \mathrm{p}<0.001)$, and oxycodone (adjusted OR $(95 \% \mathrm{CI})=2.2$ (1.7 to 2.9 ), $\mathrm{p}<0.001$ ) compared with men. The four most common types of adverse reactions were gastrointestinal (53\%), skin and subcutaneous tissue (26\%), psychiatric $(17 \%)$ and nervous system effects (15\%; see online supplemental file 1). Women had a higher risk of having gastrointestinal issues (adjusted OR $(95 \% \mathrm{CI})=3.1$ (2.3 to 4.3), $\mathrm{p}<0.001$ ), skin and subcutaneous tissue complications (adjusted OR $(95 \% \mathrm{CI})=2.1$ (1.4 to 3.3), $\mathrm{p}=0.001)$ and nervous system issues (Adjusted OR $(95 \% \mathrm{CI})=2.3$ (1.3 to 4.2), $\mathrm{p}=0.004$ ). No sex difference was found in the risk of having psychiatric issues (adjusted OR $(95 \% \mathrm{CI})=0.8$ (0.5 to 1.3$), \mathrm{p}=0.41)$. In addition, $57 \%$ of individuals reporting nervous system issues (eg, headache, dizziness) also reported issues from another MedDRA class (online supplemental figure 2), suggesting that adverse reactions in the nervous system often occur concomitantly with adverse reactions from other MedDRA classes.

Next, a secondary analysis was conducted by including persons who had an adverse reaction to an opioid, but did not have a prescription for that opioid in the study time frame or REP coverage $(n=8585$, figure $1 \mathrm{~B})$. Women again had a higher risk of having an adverse reaction to tramadol and oxycodone, but they also had a higher odds of reporting adverse reactions to codeine (adjusted OR $(95 \% \mathrm{CI})=2.3(1.8$ to 2.8$), \mathrm{p}<0.001$; see online supplemental file 1).

\section{DISCUSSION}

In a large cohort of patients, women were more likely to have EHR documentation in their allergy section indicating an adverse reaction to an opioid, and women reported different types of adverse reactions compared with men. Together, these results suggest that sex is an important biological variable to consider when prescribing opioids for pain management.

Overall, women were about twice as likely as men to have EHR information indicating an adverse reaction to an opioid medication after taking into account differences in prescription rates. However, the opioids included in this study are from different drug classes. Codeine, hydrocodone and oxycodone are phenanthrenes, a class of opioids characterised by a tricyclic aromatic hydrocarbon structure. In contrast, tramadol is not a phenanthrene and is involved in partial $\mathrm{mu}(\mu)$ agonist activity in addition to central gamma amino butyric acid, catecholamine and serotonergic activities. ${ }^{40}$ These chemical differences may affect type and occurrence of adverse reactions. ${ }^{28}$ Therefore, sex differences were also examined individually for each opioid of interest. The observed sex difference for oxycodone is consistent with previous findings indicating higher rates of adverse reactions due to opioids in women. ${ }^{7-9}$ Sex differences in adverse effects to tramadol were also observed, but studies specifically investigating sex differences in adverse reactions after tramadol administration could not be found. However, these findings are consistent with general reports indicating similar sex differences in adverse reactions due to use of other nonmorphine derivatives, such as sufentanil ${ }^{16}$ and fentanyl. ${ }^{19}$ Despite the large sample size, the relatively small number of outcomes for hydrocodone $(n=60)$ and codeine $(n=37)$ may have resulted in an inability to detect a statistically significant association.

The results also revealed that women and men had different types of adverse reactions recorded in their medical records related to opioid prescriptions. Women 
were more likely to have gastrointestinal issues, which is consistent with previous findings that women are more likely to experience nausea and vomiting. ${ }^{9} 1018$ Women were also more likely than men to report issues related to nervous system (eg, migraines, dizziness) and skin and subcutaneous tissue (eg, rash, itching). These findings differ from the results of small studies indicating no sex differences in the risk of diaphoresis, ${ }^{14}$ skin itchiness $^{15}$ and dizziness ${ }^{14}{ }^{15}$ after morphine administration. Men and women did not differ in the risk of having a note indicating psychiatric issues (eg, anxiety, hallucinations) associated with use of an opioid. This contrasts with one small study reporting that women had a higher risk of reporting 'coasting (spaced out)' and 'heavy or sluggish feeling' after morphine administration, ${ }^{15}$ although these adjectives may not be comparable to the MedDRA class category 'psychiatric issues'. Future research may be specifically powered to investigate sex differences in different psychological and psychiatric issues caused by opioid administration.

The observed sex differences remained statistically significant after controlling for BMI, suggesting that dosage effects due to differences in BMI did not account for the differences observed between men and women. The observed sex differences, therefore, may be due to other factors, such as the impact of sex hormones ${ }^{41}{ }^{42}$ and sex-differentiated neural circuitry ${ }^{9}$ in the functioning of pain perception and opioid receptors, alongside sexspecific mechanisms affecting opioid dynamics and kinetics. ${ }^{643}$ These sex differences may also be due to associations between sex and pharmacogenomics in opioid response, ${ }^{44}$ but more studies are needed to understand the role of sex on genotypes affecting the metabolism of drugs. Future research may investigate the impact of sex-specific factors (eg, menopause) in the patterns of adverse reactions due to opioids.

Some participants from the RIGHT study had indications of adverse reactions to opioids to which they were not prescribed within the time frame or within the REP coverage. Results including those participants and adverse reactions were not changed except for codeine. Most participants reporting adverse reactions to codeine were never prescribed codeine in the study timeline (94\%). The small number of adverse reactions for codeine in the main analysis $(n=37(6 \%))$ may be partially due to concerns from local healthcare providers about prior reported adverse reactions, along with the availability of newer drugs. The relatively small number of outcomes for codeine may have resulted in an inability to detect a statistically significant association.

The strengths of this study include an overall large sample size and an ability to extract information directly from the EHR. In addition, we had complete follow-up information after opioid prescription. However, there are several limitations that are common to retrospective epidemiological research studies. There was the assumption that a patient only experienced adverse reactions if indications of these outcomes were found in that patient's EHRs, and thus, this study missed adverse reactions that patients did not report to their healthcare providers (eg, patients experiencing adverse reactions without informing their healthcare provider). The results may, therefore, reflect the degree to which individuals were bothered by these symptoms rather than actual occurrence of the symptoms themselves. Moreover, men may report adverse reactions less frequently than women, ${ }^{45}$ and as such this reporting could bias the results if men (but not women) underreported adverse reactions. Active, real-time follow-up of persons prescribed these medications may be needed to disentangle symptom occurrence from other factors influencing individuals' willingness to report a symptom to healthcare providers (eg, the degree to which individuals are bothered by symptoms). In addition, opioids are frequently prescribed or used in combination with other medications (eg, adjuvant analgesics), particularly following surgical or medical procedures. Therefore, some of the reported adverse reactions may have been due to other prescriptions or other health events (such as the reason for prescription itself) that occurred at the time of the prescription and were erroneously attributed to the opioid medication. Our cohort is mostly from a non-Hispanic white population, and may not be generalisable to other groups. Our study included opioids that are commonly prescribed in the USA but that may be uncommon or not available elsewhere. Our analysis did not account for sex differences in misuse of opioids (eg, opioid use disorder, overdose) that may have contributed to different adverse reaction rates. In addition, a nocebo effect-which occurs more commonly among women ${ }^{46}$ may have affected reporting of adverse reactions. For example, oxycodone has received negative publicity over the years, ${ }^{47}$ and the risk of adverse reactions in our study was highest among women prescribed oxycodone (5\%). We investigated sex differences in the occurrence, but not in the severity, of adverse reactions. Future retrospective studies may consider investigating differences between men and women in the misuse of opioids and severity of adverse reactions due to opioid use. Finally, although this cohort was large, some adverse effects (eg, respiratory depression) were rare, and it was not possible to assess sex differences in these adverse effects.

In summary, women had more notes in their medical records indicating adverse effects following prescription of four common opioids. In addition, the types of adverse effects experienced by women differed compared with men. Healthcare providers prescribing opioids to female patients may be more likely to advise them that they may experience adverse reactions such as nausea, constipation and pruritus. At the core of individualised medicine is the identification of factors affecting how individuals metabolise and respond to drugs. These findings, therefore, support the importance of evaluating outcomes by sex in studies of opioid prescriptions and pain management. ${ }^{48}$

Acknowledgements MedDRA trademark is registered by IFPMA on behalf of $\mathrm{ICH}$. 
Contributors GSL: study design, manuscript writing. SB: data contributor, manuscript revision. AM: clinical consultant, manuscript revision. DJJ: biostatistics, manuscript revision. LW: bioinformatics, manuscript revision. RJ: biostatistics, manuscript revision. NBL: biostatistics, manuscript revision. VMM: funding contributor, manuscript revision. YZ: clinical consultant, manuscript revision. DCC: clinical consultant, manuscript revision JSS: study design, manuscript revision.

Funding This work was supported by the Mayo Clinic Specialized Center of Research Excellent on Sex Differences, the Mayo Clinic Center for Individualized Medicine, the Robert D. and Patricia E. Kern Center for the Science of Health Care Delivery, and the National Institutes of Health grants (U19 GM61388 (The Pharmacogenomics Research Network), R01 GM28157, U01 HG005137, R01 GM125633, R01 AG034676 (The Rochester Epidemiology Project), U54 AG044170 (SexSpecific Effects of Endocrine Disruption on Aging and Alzheimer's Disease)), and (U01 HG06379 and U01 HG06379 Supplement (The Electronic Medical Record and Genomics (eMERGE) Network)). This work was also supported by T32 HL071111.

\section{Competing interests None declared.}

Patient consent for publication Not required.

Provenance and peer review Not commissioned; externally peer reviewed.

Data availability statement Data are available on reasonable request. For questions regarding the RIGHT 10K study, please contact SB at Bielinski.Suzette@ mayo.edu.

Supplemental material This content has been supplied by the author(s). It has not been vetted by BMJ Publishing Group Limited (BMJ) and may not have been peer-reviewed. Any opinions or recommendations discussed are solely those of the author(s) and are not endorsed by BMJ. BMJ disclaims all liability and responsibility arising from any reliance placed on the content. Where the content includes any translated material, BMJ does not warrant the accuracy and reliability of the translations (including but not limited to local regulations, clinical guidelines, terminology, drug names and drug dosages), and is not responsible for any error and/or omissions arising from translation and adaptation or otherwise.

Open access This is an open access article distributed in accordance with the Creative Commons Attribution Non Commercial (CC BY-NC 4.0) license, which permits others to distribute, remix, adapt, build upon this work non-commercially, and license their derivative works on different terms, provided the original work is properly cited, appropriate credit is given, any changes made indicated, and the use is non-commercial. See: http://creativecommons.org/licenses/by-nc/4.0/.

\section{ORCID iDs}

Guilherme S Lopes http://orcid.org/0000-0003-2923-2721

Suzette Bielinski http://orcid.org/0000-0002-2905-5430

Jennifer St Sauver http://orcid.org/0000-0002-9789-8544

\section{REFERENCES}

1 Roehler DR. Centers for Disease Control and Prevention (CDC). In: Annual surveillance report of drug-related risks and outcomes, 2019. https://www.cdc.gov/drugoverdose/pdf/pubs/2019-cdc-drugsurveillance-report.pdf

$2 \mathrm{Li} \mathrm{PH}, \mathrm{Ue} \mathrm{KL}$, Wagner A, et al. Opioid hypersensitivity: predictors of allergy and role of drug provocation testing. J Allergy Clin Immunol Pract 2017;5:1601-6.

3 Fillingim RB. Individual differences in pain: understanding the mosaic that makes pain personal. Pain 2017;158 Suppl 1:S11-18.

4 Fillingim RB, Gear RW. Sex differences in opioid analgesia: clinical and experimental findings. Eur J Pain 2004;8:413-25.

5 Fullerton EF, Doyle HH, Murphy AZ. Impact of sex on pain and opioid analgesia: a review. Curr Opin Behav Sci 2018;23:183-90.

6 Averitt DL, Eidson LN, Doyle HH, et al. Neuronal and glial factors contributing to sex differences in opioid modulation of pain. Neuropsychopharmacology 2019;44:155-65.

7 Bijur PE, Esses D, Birnbaum A, et al. Response to morphine in male and female patients: analgesia and adverse events. Clin J Pain 2008;24:192-8.

8 Comer SD, Cooper ZD, Kowalczyk WJ, et al. Evaluation of potential sex differences in the subjective and analgesic effects of morphine in normal, healthy volunteers. Psychopharmacology 2010;208:45-55.

9 Doyle HH, Murphy AZ. Sex differences in innate immunity and its impact on opioid pharmacology. J Neurosci Res 2017;95:487-99.

10 Sadhasivam S, Chidambaran V, Olbrecht VA, et al. Opioidrelated adverse effects in children undergoing surgery: unequal burden on younger girls with higher doses of opioids. Pain Med 2015;16:985-97.

11 Zacny JP, Apfelbaum SM, Perkins KA. Modulating roles of smoking status and sex on oxycodone-induced nausea and drug liking. Exp Clin Psychopharmacol 2013;21:103-11.

12 Lofwall MR, Nuzzo PA, Walsh SL. Effects of cold pressor pain on the abuse liability of intranasal oxycodone in male and female prescription opioid abusers. Drug Alcohol Depend 2012;123:229-38.

13 Sinclair DR, Chung F, Mezei G. Can postoperative nausea and vomiting be predicted? Anesthesiology 1999;91:109-18.

14 Fillingim RB, Ness TJ, Glover TL, et al. Morphine responses and experimental pain: sex differences in side effects and cardiovascular responses but not analgesia. J Pain 2005;6:116-24.

15 Zacny JP. Morphine responses in humans: a retrospective analysis of sex differences. Drug Alcohol Depend 2001;63:23-8.

16 Schnabel A, Poepping DM, Gerss J, et al. Sex-Related differences of patient-controlled epidural analgesia for postoperative pain. Pain 2012;153:238-44.

17 Cepeda MS, Farrar JT, Baumgarten M, et al. Side effects of opioids during short-term administration: effect of age, gender, and race. Clin Pharmacol Ther 2003;74:102-12. 102-12.

18 Daoust R, Paquet J, Lavigne G, et al. Impact of age, sex and route of administration on adverse events after opioid treatment in the emergency department: a retrospective study. Pain Res Manag 2015;20:23-8.

19 Graff KJ, Kennedy RM, Jaffe DM. Conscious sedation for pediatric orthopaedic emergencies. Pediatr Emerg Care 1996;12:31-5.

20 Sarton E, Teppema L, Dahan A. Sex differences in morphine-induced ventilatory depression reside within the peripheral chemoreflex loop. Anesthesiology 1999;90:1329-38.

21 Romberg R, Olofsen E, Sarton E, et al. PharmacokineticPharmacodynamic modeling of morphine-6-glucuronide-induced analgesia in healthy volunteers: absence of sex differences. Anesthesiology 2004;100:120-33.

22 Zacny JP, Drum M. Psychopharmacological effects of oxycodone in healthy volunteers: roles of alcohol-drinking status and sex. Drug Alcohol Depend 2010;107:209-14.

23 Comer SD, Ashworth JB, Sullivan MA, et al. Relationship between rate of infusion and reinforcing strength of oxycodone in humans. $J$ Opioid Manag 2009;5:203-12.

24 Dahan A, Sarton E, Teppema L, et al. Sex-Related differences in the influence of morphine on ventilatory control in humans. Anesthesiology 1998;88:903-13.

25 Guo L, Luo M, Wang W, et al. Association between nonmedical use of opioids or sedatives and suicidal behavior among Chinese adolescents: an analysis of sex differences. Aust N Z J Psychiatry 2019;53:559-69.

26 Zacny JP, Gutierrez S. Characterizing the subjective, psychomotor, and physiological effects of oral oxycodone in non-drug-abusing volunteers. Psychopharmacology 2003;170:242-54

27 Kaplovitch E, Gomes T, Camacho X, et al. Sex differences in dose escalation and overdose death during chronic opioid therapy: a population-based cohort study. PLoS One 2015;10:e0134550.

28 Trescot AM, Datta S, Lee M. Opioid pharmacology. Pain Physician 2008;11:S133-53.

29 Ji Y, Skierka JM, Blommel JH, et al. Preemptive pharmacogenomic testing for precision medicine: a comprehensive analysis of five actionable pharmacogenomic genes using next-generation DNA sequencing and a customized CYP2D6 genotyping cascade. J Mol Diagn 2016;18:438-45.

30 Bielinski SJ, Olson JE, Pathak J, et al. Preemptive genotyping for personalized medicine: design of the right drug, right dose, right time-using genomic data to individualize treatment protocol. Mayo Clin Proc 2014;89:25-33.

31 Bielinski SJ, St Sauver JL, Olson JE, et al. Cohort profile: the right drug, right dose, right time: using genomic data to Individualize treatment protocol (right protocol). Int J Epidemiol 2020;49:23-4.

32 Olson JE, Ryu E, Johnson KJ, et al. The Mayo clinic Biobank: a building block for individualized medicine. Mayo Clin Proc 2013;88:952-62.

33 Blumenthal KG, Acker WW, Li Y, et al. Allergy entry and deletion in the electronic health record. Ann Allergy Asthma Immunol 2017;118:380-1.

34 Gilbar PJ, Ridge AM. Inappropriate labelling of patients as opioid allergic. J Oncol Pharm Pract 2004;10:177-82.

35 Saljoughian M. Allergy vs pseudoallergy. Opioids 2006:5-9 https:// www.uspharmacist.com/article/opioids-allergy-vs-pseudoallergy

36 Liu H, Bielinski SJ, Sohn S, et al. An information extraction framework for cohort identification using electronic health records. AMIA Jt Summits Trans/ Sci Proc 2013;2013:149-53. 
37 St Sauver JL, Grossardt BR, Yawn BP, et al. Data resource profile: the Rochester epidemiology project (Rep) medical records-linkage system. Int J Epidemiol 2012;41:1614-24.

38 Rocca WA, Grossardt BR, Brue SM, et al. Data resource profile: expansion of the Rochester epidemiology project medical recordslinkage system (E-REP). Int J Epidemiol 2018;47:368-368j.

39 Hope ACA. A simplified Monte Carlo significance test procedure. Journal of the Royal Statistical Society: Series B 1968;30:582-98.

40 Drewes AM, Jensen RD, Nielsen LM, et al. Differences between opioids: pharmacological, experimental, clinical and economical perspectives. Br J Clin Pharmacol 2013;75:60-78.

41 McEwen BS, Milner TA. Understanding the broad influence of sex hormones and sex differences in the brain. $J$ Neurosci Res 2017;95:24-39.

42 Chartoff EH, Mavrikaki M. Sex differences in kappa opioid receptor function and their potential impact on addiction. Front Neurosci 2015;9:466.
43 Soldin OP, Chung SH, Mattison DR. Sex differences in drug disposition. J Biomed Biotechnol 2011;2011:1-14.

44 Lopes GS, Bielinski SJ, Moyer AM, et al. Sex differences in associations between CYP2D6 phenotypes and response to opioid analgesics. Pharmgenomics Pers Med 2020;13:71-9.

45 Sousa-Pinto B, Fonseca JA, Gomes ER. Frequency of self-reported drug allergy: a systematic review and meta-analysis with metaregression. Ann Allergy Asthma Immunol 2017;119:e2:362-73.

46 Vambheim SM, Flaten MA. A systematic review of sex differences in the placebo and the nocebo effect. J Pain Res 2017;10:1831-9.

47 Ostling PS, Davidson KS, Anyama BO, et al. America's opioid epidemic: a comprehensive review and look into the rising crisis. Curr Pain Headache Rep 2018;22:32.

48 National Institutes of Health. Inclusion of Women and Minorities as Participants in Research Involving Human Subjects, 2017. Available: https://grants.nih.gov/policy/inclusion/women-andminorities.htm 